J. Lake Sci. (湖泊科学) , 2015, 27 (6): 1177-1186

DOI 10. 18307/2015. 0624

(C) 2015 by Journal of Lake Sciences

\title{
基于马尔科夫链模型的鄱阳湖流域水文气象干旱研究”
}

孙 鹏 ${ }^{1,2}$, 张 强 ${ }^{2,3,4 * *}$, 涂新军 ${ }^{2,3,4}$, 江 涛 $2,3,4$

(1: 安徽师范大学国土资源与旅游学院, 芜湖 241003)

(2: 中山大学水资源与环境系, 广州 510275)

(3: 中山大学华南地区水循环与水安全广东省普通高校重点实验室, 广州 510275 )

(4: 江西师范大学鄱阳湖湿地与流域研究教育部重点实验室, 南昌 330022)

摘 要: 基于气象和水文干旱的二维变量干旱状态基础上, 通过一阶马尔科夫链模型对二维变量干旱状态进行频率、重 现期和历时分析, 建立水文气象干旱指数, 从干旱灾害形成、演变和持续 3 方面对干旱灾害进行研究, 同时预测未来 6 个 月非水文干旱到水文干旱的概率. 结果表明: (1) 修河流域在干旱形成中危害大, 抚河流域和修河流域在干旱演变中危害 大, 赣江流域和饶河流域在干旱持续中危害大; (2) 鄱阳湖流域状态 4 (气象、水文干旱) 发生的频率最高, 为 0.30 , 连续湿 润或者干旱的概率最大, 湿润状态 (状态 2) 与水文干早 (状态 4 、状态 5 (气象湿润、水文干旱) ) 的相互转移概率最低; (3) 在长期干旱预测中, 鄱阳湖流域从状态 2 转到状态 4 和状态 5 的平均概率为 0.11 , 属最低, 而状态 1 (气象、水文无旱) 和状态 3 (气象干旱、水文湿润) 到达状态 4 的概率为 0.23 , 发生概率最大. 修河流域在非水文干旱状态下未来发生气象、 水文干旱状态的平均概率为 0.28 , 是 “五河” 中最高的, 而赣江流域在正常或者湿润状态下未来发生气象、水文干旱的概 率最低,为 0.18 , 该研究对于鄱阳湖流域水文气象干旱的抗旱减灾具有重要理论与现实意义.

关键词: 水文气象干旱指数; 干旱状态转移; 干旱预测 ; 马尔科夫链模型; 鄱阳湖流域

\section{Changing properties of meteor-hydrological droughts of the Lake Poyang Basin using the Markov model}

SUN Peng ${ }^{1,2}$, ZHANG Qiang ${ }^{2,3,4}$, TU Xinjun ${ }^{2,3,4}$ \& JIANG Tao ${ }^{2,3,4}$

(1: College of Territorial Resources and Tourism, Anhui Normal University, Wuhu 241003, P. R. China)

(2: Department of Water Resources and Environment, Sun Yat-sen University, Guangzhou 510275, P. R. China)

(3: Key Laboratory of Water Cycle and Water Security in Southern China of Guangdong High Education Institute, Sun Yat-sen University, Guangzhou 510275 , P. R. China)

(4: Key Laboratory of Poyang Lake Wetland and Watershed Research, Ministry of Education, Jiangxi Normal University, Nanchang 330022, P. R. China)

Abstract: Combined analysis of precipitation and water scarcity was done with using SPI and SRI indices. Time series of the
hydro-meteorological conditions were investigated as discrete state, discrete-time Markov chain with aim to explore transition be-
tween drought conditions in terms of frequency, residence time, and interim period from one drought condition to another. Besides,
prediction of drought conditions were also conducted. The results indicate that: ( 1 ) The drought hazards do have its massive nega-
tive impacts during its initial conditions in the Xiuhe River basin; and manifest its negative impacts during its developing conditions
of the droughts in the Fuhe and Xiuhe River basins; in the Ganjiang and Raohe River basins, however, the droughts have its grea-
test impacts during lasting time intervals; (2) The occurrence probability of meteor-hydrological droughts of the Poyang Lake is
characterized by continuing wet or dry conditions. Transition between meteorological wetness to hydrological drought is subject to
lower probability in the Lake Poyang Basin; (3) The prediction of droughts indicates that the transitional probability from the 2 nd

* 鄱阳湖湿地与流域研究教育部重点实验室主任开放基金项目 (ZK2013006)、国家杰出青年科学基金项目 (51425903) 和安徽师范大学博士科研启动金项目和安徽省自然科学基金项目 (1408085 MKL23) 联合资助. 2014-11-11 收稿;2015-03-12 收修改稿. 孙鹏(1986 ), 男, 博士, 副教授; E-mail:sun68peng@ 163. com.

** 通信作者;E-mail: zhangq68@ mail. sysu. edu. cn. 
condition to hydrological drought is the lowest and the transitional probability from the 1 st (or 3rd) condition to the 4th condition is the largest. The transitional probability from the 1st, 2nd and 3rd condition to hydrological drought is the lowest in Xiuhe River Basin. However, The transitional probability from the $1 \mathrm{st}$ and 2 nd condition to hydrological drought is the largest in Ganjiang River Basin The results of this study will be of great merits in terms of human mitigation to droughts in a changing environment.

Keywords: Meteor-hydrological drought index; transition of drought conditions; drought prediction; Markov Model; Lake Poyang Basin

鄱阳湖是我国目前最大的淡水湖泊、同时也是长江干流重要的调蓄性湖泊,在长江流域发挥着巨大的 调蓄洪水和保护生物多样性等特殊生态与防洪功能. 鄱阳湖是我国十大生态功能保护区之一, 也是世界自 然基金会划定的全球重要生态区之一 ${ }^{[1-2]}$. 自 1990s 以来, 鄱阳湖流域洪水和干旱事件发生的频率不断增 加, 特别是极端干旱和洪水事件发生频率增加 ${ }^{[3-5]}, 21$ 世纪以来, 流域的干旱程度不断加剧, 2003、2006 和 2007 年的持续枯水事件和 2011 年的旱涝急转事件, 导致鄱阳湖几近枯竭, 严重威胁着湖区上千万居民的用 水安全,并引起人们的高度关注.

国内外学者对鄱阳湖流域的水文特征 ${ }^{[6-7]}$ 和洪、枯水特征 ${ }^{[1,8-9]}$ 进行大量研究, 同时对于鄱阳湖流域干旱 的气候特征进行研究, 揭示气候变化对流域内干旱变化的影响 ${ }^{[10-12]}$. 尽管对于鄱阳湖流域的干旱研究较多, 但是大部分研究区域集中于鄱阳湖区或者仅从气象干旱角度研究鄱阳湖流域的干旱特征. 干旱主要分为气 象干旱、水文干旱、农业干旱和社会经济干旱四类 ${ }^{[13]}$, 对于鄱阳湖流域水文干旱研究甚少, 且运用多个干旱 指标, 特别是将水文干旱和气象干旱相结合的干旱研究尚未深人开展. 基于此, 本文建立基于气象干旱与水 文干旱指标相结合的二维干旱状态变量, 运用马尔科夫链模型, 从干旱灾害形成、演变和持续方面对鄱阳湖 流域干旱灾害进行研究, 同时预测未来 6 个月非水文干旱到水文干旱的概率, 该项研究对鄱阳湖流域的抗 旱具有重要的科学与现实意义.

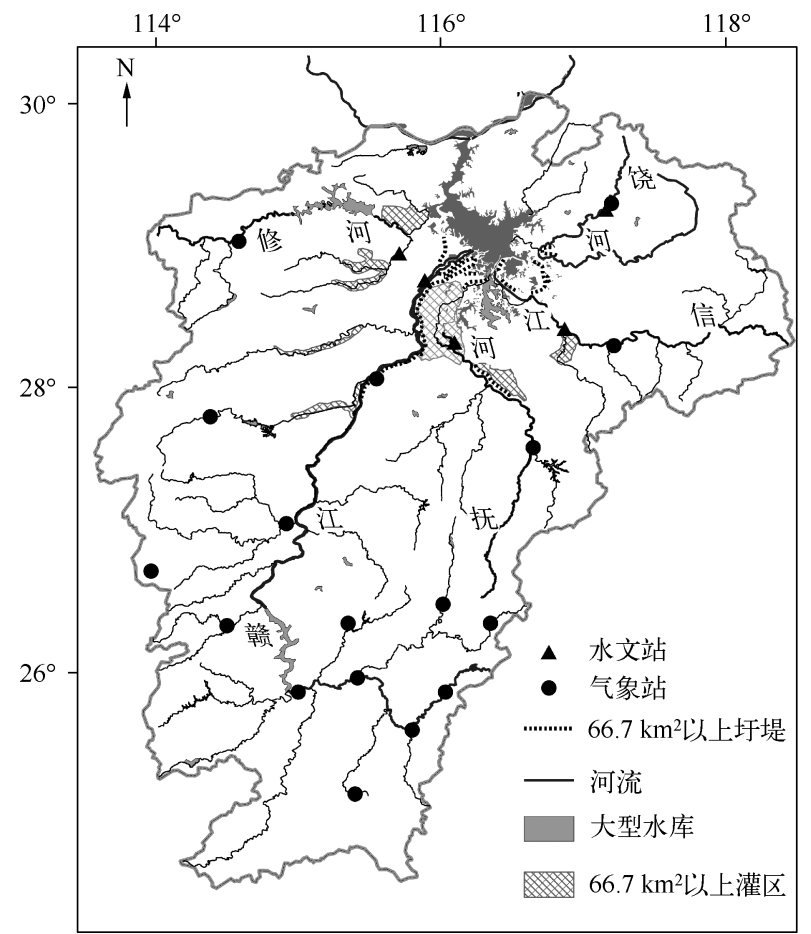

图 1 鄱阳湖流域水文站点、气象站点以及 水库地理位置示意

Fig. 1 Location of hydrological stations, meteorological stations, water reservoirs in the Lake Poyang Basin

\section{1 数据来源}

本文所用数据为鄱阳湖流域主要水文 控制站 (外洲、李家渡、梅港、渡峰坑和万家 埠) 1956-2005 年长序列月径流量资料, 资 料来源于江西省水文局; 水文控制站上游相 近的主要气象站 1956-2005 年长序列月降 雨量, 资料来源于国家气象中心 (图 1). 本 数据具有一定的代表性, 径流量缺失的数 据, 取缺失数据的前后 $3 \mathrm{~d}$ 的平均值, 缺失的 降雨量通过建立线性回归方程进行计算.

\section{2 方法}

\section{$2.1 S P I-S R I$ 干旱指数}

标准化径流指数 (standardized runoff in$\mathrm{dex}, S R I)$ 是以 McKee 提出的标准化降雨指 数 (standardized precipitation index, SPI) 为理 论依据的 ${ }^{[14]}$. 本文中径流量是用月径流量 中值计算, 与月平均径流量相比较, 月径流 量的中值不受枯水季节的某时段连续降水 的影响, 能很好地代表枯水季节的径流量. SPI 的原理就是 McKee 等提出 ${ }^{[15]}$ 用伽马 ( Г) 分布概率密度函数计算某一时间尺度的 降水量累积概率. 为消除样本的自相关性, 
将时间序列中不同月份的 SPI 值先分别计算, 再合起来得到整个时间序列的 SPI 值. 假定计算时间尺度为 $m$ 个月的标准降水指标 (通常 $m$ 取 3、6、12、24 等), 依次对连续 $m$ 个月的月降水资料求和, 得到 $m$ 个月累积 降水序列. 在累积降水序列中, 选取所有年份中某个月份的值,形成另一个序列 (例如选取 1956-2005 年 7 月份的值), 采用 Gamma 分布对其配线, 配线完成后, 计算累积降水的累积概率, 再通过标准正态分布反函 数转换为标准正态分布, 所得结果即是该月份的标准降水指标值, 具体计算公式及步骤参考文献 [15-16]. 短时间尺度 (1、3、6 月等) 的 $S R I$ 和 $S P I$ 值可以反映农作物在生长期的水分供给情况 ${ }^{[16]}$. 由于鄱阳湖流域以 季节性干旱为主, 鄱阳湖流域短时期的干旱对于农业生产威胁最大 ${ }^{[11]}$, 因此本文计算 $S P I$ 的尺度采用 3 个月.

本文建立一个新的二维变量的干旱状态— SPI-SRI 对鄱阳湖流域干旱进行研究. SPI 和 SRI 都服从均 值和方差相同的正态分布, SPI 和 SRI 的相关系数是双正态分布散点图 (图 2), 根据 Eyton 对二维变量的相 关系数分级方法 ${ }^{[17]}$, 利用双正太分布特性和等概率椭圆划分无旱状态. 根据 Guttman 定义 SPI 的无旱值是 $[-0.5,0.5]$, 本文定义 $S R I$ 无旱值的范围也是 $[-0.5,0.5]$, 因此无旱等级点必须满足 $S P I$ 和 $S R I$ 介于 -0.5 和 0.5 之间, 同时无旱等级点也必须满足距原点 $(0,0)$ 的马氏距离小于 0.5 . 马氏距离表示数据的协 方差距离, 它是一种有效的计算 2 个未知样本集相似度的方法. 与欧氏距离不同的是, 它考虑到各种特性 之间的联系, 还可以排除变量之间相关性的干扰. 这些小于 0.5 马氏距离的 SPI-SRI 二维变量点形成一个等 概率的椭圆, 椭圆内的点划分为正常状态, 椭圆外的 SPI-SRI 二维变量点划分等级依据 SPI 和 SRI 值与 0 之 间的关系,本文将 SPI-SRI 二维变量划分为 5 个等级,具体见表 1 .

表 $1 S P I-S R I$ 二维联合干旱指标的状态划分

Tab. 1 SPI-SRI categories

\begin{tabular}{ccccc}
\hline 状态 & & $S P I$ 值 & $S R I$ 值 & 马氏距离 $D$ \\
\hline 状态 1 & 气象、水文无早 & $-0.5 \leqslant S P I \leqslant 0.5$ & $-0.5 \leqslant S R I \leqslant 0.5$ & $D<0.5$ \\
状态 2 & 气象、水文湿润 & $S P I>0.5$ & $S R I>0.5$ & $D \geqslant 0.5$ \\
状态 3 & 气象干旱、水文湿润 & $S P I<-0.5$ & $S R I>0.5$ & $D \geqslant 0.5$ \\
状态 4 & 气象、水文干早 & $S P I<-0.5$ & $S R I<-0.5$ & $D \geqslant 0.5$ \\
状态 5 & 气象湿润、水文干早 & $S P I>0.5$ & $S R I<-0.5$ & $D \geqslant 0.5$ \\
\hline
\end{tabular}

\section{2 马尔科夫链}

设马尔科夫链有 $S$ 个状态, 记转移状态为 $1,2, \cdots, m$, 某一转移时刻的状态为 $S$ 个状态之一, 转移 概率 $p_{i j}{ }^{[18]}$ 为:

$$
\begin{gathered}
p_{i j}(n, k)=P\left(X_{n+k}=j \mid X_{n}=i\right)(i, j=1,2, \ldots, m ; n, k \text { 为正整数 }) \\
p_{i j}=n_{i j} / \sum_{i=1}^{S} n_{i j}
\end{gathered}
$$

式中, $p_{i j}(n, k)$ 为过程从时刻 $n$ 状态 $j$ 经 $k$ 步转移到状态 $j$ 的概率. 一般而言 $p_{i j}(n, k)$ 与 $i, j, k$ 和 $n$ 有关. 当 $p_{i j}(n, k)$ 与 $i, j, k$ 和 $n$ 无关 (与初始状态无关) 时, 则称为齐次马尔科夫链. 通过转移概率 $p_{i j}$ 分别计算 $X_{0}$ 到 $X_{m}$ 的连续 $m$ 个月的状态均是 $i$ 的期望滞留时间和状态 $i$ 到状态 $j$ 的平均首达时间 ${ }^{[19]}$.

一阶马尔科夫模型并不一定能很好地分析时间序列过程, 本文运用 AIC 模型 ${ }^{[20]}$ 对一阶马尔科夫模型和 二阶马尔科夫模型进行评估, $A I C$ 值越低, 表明模型越适合鄱阳湖流域.

$$
A I C(r)=-2 L_{r}+S^{r}(S-1)
$$

其中, $L_{1}$ 和 $L_{2}$ 分别为:

$$
\begin{gathered}
L_{1}=\sum_{i=0}^{S} \sum_{j=0}^{S} n_{i j} \cdot \ln \left(p_{i j}\right) \\
L_{2}=\sum_{h=0}^{S} \sum_{i=0}^{S} \sum_{j=0}^{S} n_{h i j} \cdot \ln \left(p_{h i j}\right)
\end{gathered}
$$


式中, $L_{1} 、 L_{2}$ 分别表示一阶和二阶马尔科夫链模型的对数似然值.

在计算马尔科夫链模型之前必须检验随机过程是否满足马氏性, 本文运用 $\chi^{2}$ 检验法检验马尔科夫链的 马氏性 ${ }^{[20]}$. 当样本容量足够大时, 统计量:

$$
\begin{gathered}
\chi^{2}=\sum_{i=0}^{S} \sum_{j=0}^{S} \frac{\left(n_{i j}-e_{i j}\right)^{2}}{e_{i j}} \\
e_{i j}=\frac{\sum_{j=0}^{S} n_{i j} \cdot \sum_{i=0}^{S} n_{i j}}{n}
\end{gathered}
$$

式中, $n$ 为样本总量.

\section{3 结果与分析}

\section{1 综合干旱指标分析}

鄱阳湖流域赣江、抚河、信江、饶河和修水的 SPI-SRI 综合干旱指数相关系数见图 2 , 根据表 2 的分级标 准, 将 SPI-SRI 综合干旱指数划分为 5 个状态, 椭圆内的点代表状态 1 , 根据干旱形成过程, 状态 3 代表干旱 的初始阶段一气气象干旱, 由于连续无降水引起地表水资源量的减少, 形成了水文干旱 (状态 4); 然后降水 事件发生, 气象干旱得以恢复到正常或者湿润状态, 但是不足以立刻恢复水文干旱到正常或者湿润状态, 因 此状态 5 代表气象不干旱、水文干旱的状态. 如果降水足以恢复水文干旱到正常或者湿润状态的时候, 这时 就有状态 5 转向状态 1 或者状态 2 . 根据公式 $(3) \sim(5)$, 鄱阳湖流域各站点数据均满足马氏性. 通过 $A I C$ 模型对一阶、二阶马尔科夫链模型进行评估, 发现赣江、抚河、信江、饶河和修河的一阶马尔科夫链模型 $A I C$ 值 (1062、1310、1260、1262 和 1399) 远低于二阶马尔科夫链模型 $A I C$ 值 $(2134 、 2591 、 2454 、 2467$ 和 2757), 因 此本文选择一阶马尔科夫链模型作为预测 SPI-SRI 综合干旱指数的模型. 图 3 显示鄱阳湖流域 SPI-SRI 变 化趋势基本一致, 在 $1950 \mathrm{~s}-1960 \mathrm{~s}$ 和 $1980 \mathrm{~s}$, 鄱阳湖流域以干旱为主; 进人 1990s 以后, 鄱阳湖流域以洪涝为 主,但是 2000 年之后流域有干旱趋势,其他时间段旱涝交替发生.

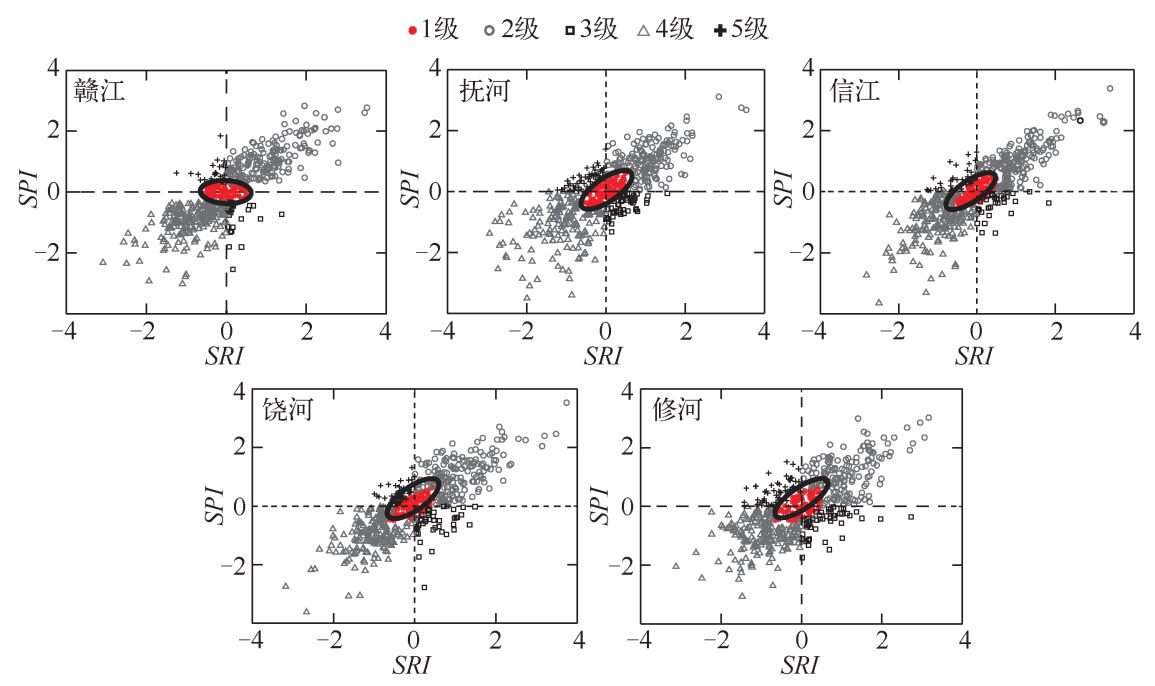

图 2 鄱阳湖流域水文站和气象站对应综合干旱指数的相关关系

Fig. 2 The SRI and SPI correlation plots for the coupled hydrological stations and meteorological stations in Lake Poyang Basin

从整体上来说, 赣江流域状态 1 的发生频率最大 $(0.563)$, 其次是状态 4 和状态 2 ; 其他 “四河” 状态 2 和 状态 4 发生的频率高, 平均发生频率达 0.283 和0.297. 赣江流域的状态 3 和状态 5 发生频率低于其他 “四 
河”, 但是鄱阳湖流域 “五河” 的状态 3 和状态 5 发生的概率远低于其他状态, 这表明鄱阳湖流域单独的气象 干旱或者水文干旱发生频率低, 而气象干旱和水文干旱同旱或者同涝的频率高. 从年内分布来开, 鄱阳湖流 域的不同月份干旱状态 1 、状态 2 和状态 4 占的频率最大, 赣江流域各月状态 1 发生频率最高, $1-4$ 月和 7 月状态 4 发生频率大于状态 2 , 表明该时段的干旱发生频率大; 抚河流域、信江流域、饶河流域和修河流域各 月主要以状态 2 和状态 4 为主, 其中抚河流域 $1-3 、 5-6$ 和 11 月状态 4 发生频率高, 信江流域在 $1-2 、 5-9$ 月和 12 月状态 4 发生频率高, 饶河流域状态 4 发生高的月份集中在 1-2、5-8 和 10-12 月. 而修河流域 在 4-10 月状态 4 发生概率高, 其易发生干旱的月份大于其他流域, 赣江和抚河月平均发生状态 4 的概率低 于信江、饶河和修河 (图 4).

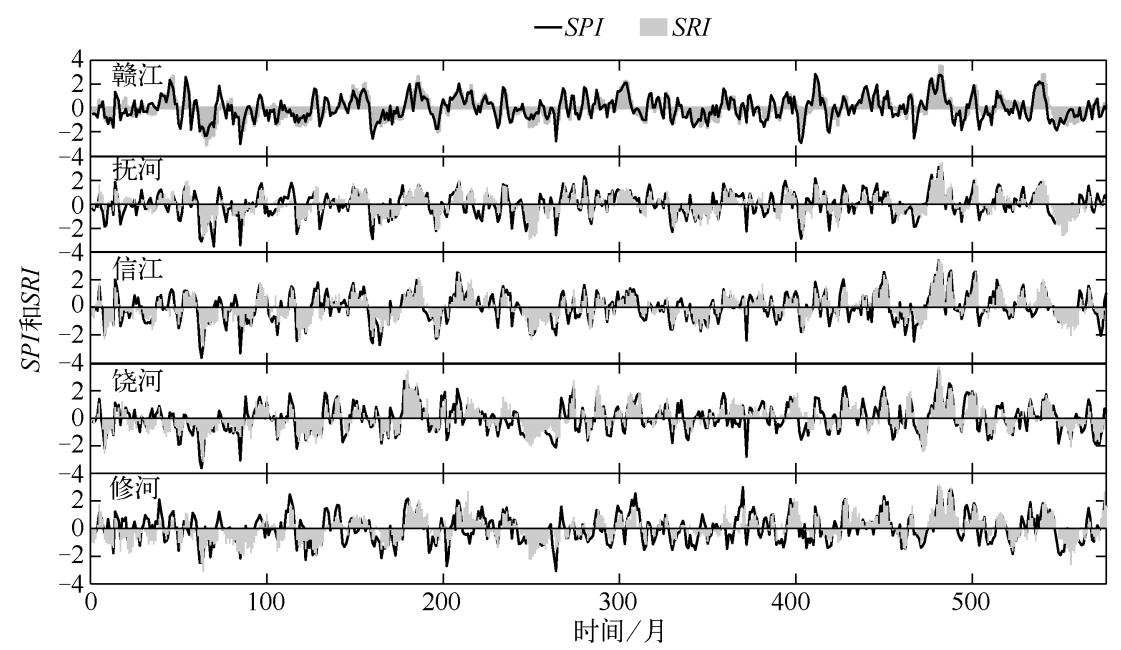

图 3 鄱阳湖流域 $S R I$ 和 $S P I$ 示意

Fig. 3 The time series of SRI and SPI values in Lake Poyang Basin

\section{2 综合干旱指标的状态转移概率}

鄱阳湖流域 “五河” 的各等级之间的转移概率 (表 2) 可以看出, 鄱阳湖流域状态 2 之间的一步转移概率 (连续湿润) 和状态 4 之间的一步转移概率 (连续干旱) 是各个流域中概率最高的, 分别达到 0.67 和 0.65 , 表明鄱阳湖流域连续湿润或者干旱的概率最大. 赣江流域的状态 1 连续发生的概率 $(0.66)$ 高于其他流域, 而状态 2 、状态 3 和状态 5 发生的概率低于其他流域. 饶河流域状态 4 之间一步转移概率 $(0.72)$ 高于其他 流域. 抚河流域状态 4 转到状态 5 的概率 $(0.17)$ 大于其他流域, 鄱阳湖流域状态 5 转到状态 2 或者状态 4 的概率基本一致,这反映了状态 5 后趋向干旱或者湿润的概率相同. 鄱阳湖流域中状态 2 和状态 4 、状态 2 和状态 5 、状态 3 和状态 5 之间的相互转移概率均小于 0.1 (赣江流域概率是 0 ), 远远低于其他状态之间的 转移概率, 这反映了湿润状态 (状态 2 ) 与水文干旱 (状态 4 、状态 5 ) 的相互转移概率低, 湿润状态必须经历 气象干旱才能发生水文干旱, 水文干旱必须经历气象不干旱才能达到湿润状态. 赣江流域其他状态一步转 移到状态 3 和状态 5 的概率远小于其他地区, 特别是状态 2 和状态 4 的一步转移概率远低于其他流域, 状 态 3 一步转移到状态 4 的概率高于其他流域.

\section{3 综合干旱指标的重现期和历时}

由有限序列计算所得的转移概率是一个与初始阶段各状态分布有密切联系的条件概率. 但是马尔科夫 链概型的理论研究已经证明, 随着过程的发展, 初始阶段的影响逐渐消失, 因而当 $n$ 趋向于无穷大时, 体系 在时间 $n$ 处于状态 $j$ 的概率不依赖于在时刻 0 的初始状态, 绝对概率分布收玫于一个独立于初始转移矩阵 的极限分布. 不同流域各等级的重现期可知, 鄱阳湖流域和状态 4 的重现期最小 (3.5 个月), 其发生的频率 最高, 其次是状态 2 的重现期 (3.9 个月) (图 5a). 状态 5 的重现期最大 (26.7 个月), 发生频率最低, 其次是 状态 3 , 且状态 3 和状态 5 重现期远大于其他状态, 这进一步表明鄱阳湖流域单独气象干旱或者水文干旱发 生的频率低. 从流域来看, 赣江流域各状态重现期差别最大, 赣江流域状态 3 和状态 5 的重现期最大, 而信 

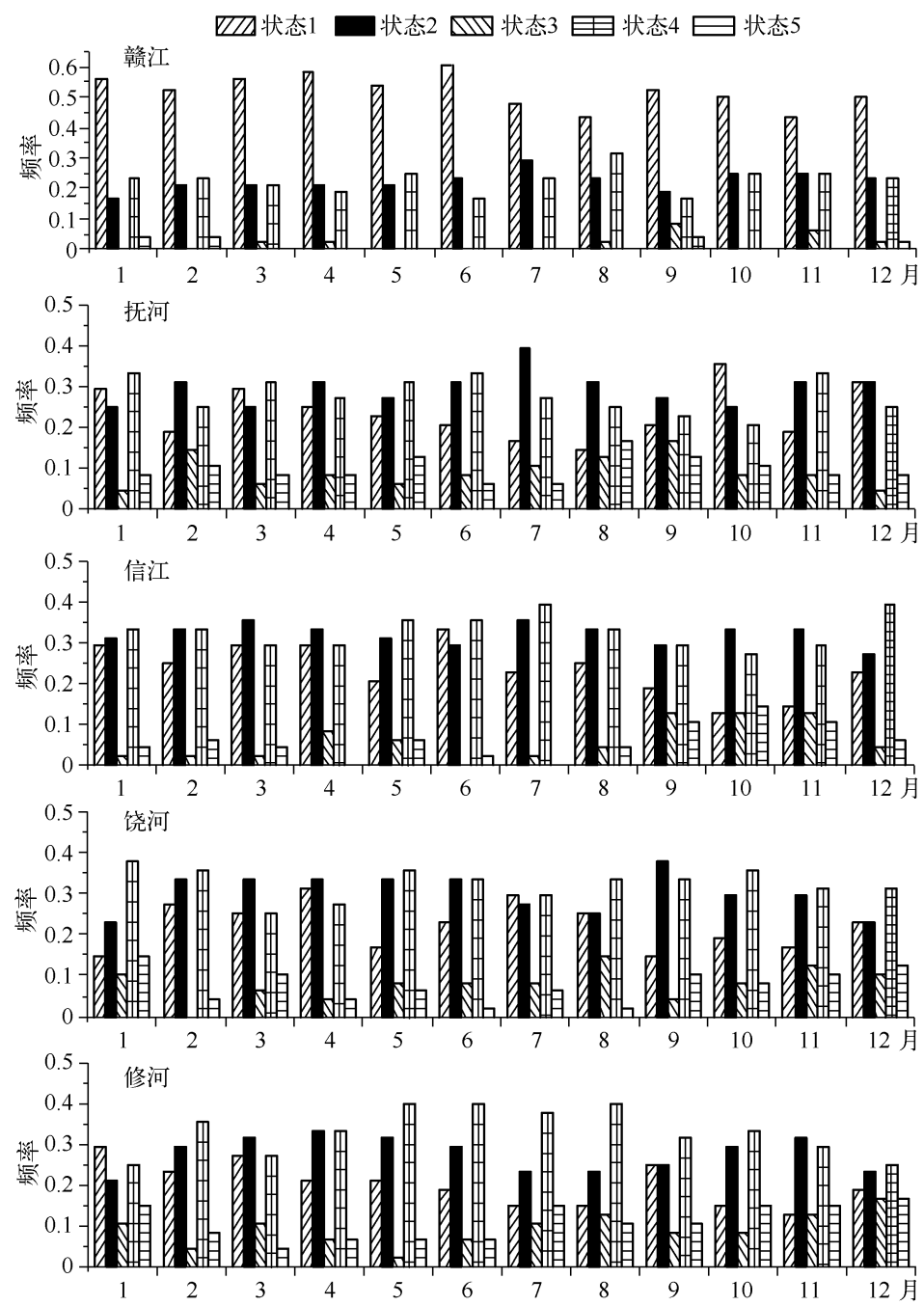

图 4 鄱阳湖流域不同月份 5 种状态出现的频率

Fig. 4 Frequency of five states in different months in Lake Poyang Basin

江流域各状态重现期差别最大, 其次是饶河流域, 信江流域状态 3 和状态 5 重现期长达 17.4 和 18.0 个月, 状态 2 和状态 4 的重现期则分别是 3.1 和 3.0 个月,抚河流域和修河流域的重现期变化与信江流域基本 一致.

鄱阳湖流域各状态的期望停留时间, 即各状态的历时见图 5b. 鄱阳湖流域状态 1 的历时最小 $(2.0$ 个 月), 状态 2 和状态 4 的历时最大 (2.9 个月), 饶河流域状态 5 的历时最大 ( 3.8 个月). 饶河流域各状态平 均历时最大(3.0 个月), 抚河流域的平均历时最小 (2.4 个月). 饶河和信江状态 2 的历时最大 ( 3.0 个月), 状态 4 和状态 5 的饶河流域的历时也高于其他流域, 这说明饶河流域和信江流域湿润状态或者干旱状态持 续时间长. 赣江流域的状态 4 和状态 5 的历时是流域中最小的, 状态 1 的历时远大于其他流域, 这表明赣江 流域干旱持续时间短, 状态 1 历时最长.

\section{4 干旱灾害特征分析}

利用计算各等级的平均首达时间演绎干旱灾害形成、演化和持续性(图 6A), 干旱灾害历时是指从一个 状态到另一个状态经历的时间 (以月为单位). 干旱灾害分为干旱灾害形成、干旱灾害演变和干旱灾害持续 3 个阶段, 干旱灾害形成历时主要从湿润状态或正常状态到气象干旱、水文干旱经历的时间; 干旱灾害演变 
历时主要包括气象干旱、水文不干旱状态到水文干旱状态的历时 (状态 3 到状态 4 ) 和气象、水文干旱到气象 不干旱、水文干旱状态的历时 (状态 4 到状态 5 ) ; 干旱灾害持续历时主要包括水文干旱状态到正常状态、湿 润状态的历时 (状态 4 或状态 5 到状态 1 或状态 2). 图 $6 \mathrm{~A}$ 中点越趋向于圆心处, 平均首达时间越大, 表明 干旱形成缓慢, 但是到达湿润状态的周期短, 点离圆心越远, 平均首达时间越小, 表明干旱形成较快, 但是到 达湿润状态的周期长, 干旱灾害的危害性越大. 然而干旱持续时间首达时间越大, 到达湿润状态的周期越 长, 干旱灾害越严重, 为了保持与干旱灾害形成、干旱灾害演变的危险方向的一致性, 将干旱灾害持续以反 向显示. 图 6A 箭头指示方向, 表示干旱灾害的危险性由小到大的趋势.

表 2 鄱阳湖流域各状态的一步转移概率*

Tab. 2 One-step transition probability matrix in Lake Poyang Basin

\begin{tabular}{cccccccccccccc}
\hline 流域 & 状态 & 1 & 2 & 3 & 4 & 5 & 流域 & 状态 & 1 & 2 & 3 & 4 & 5 \\
\hline 赣江 & 状态 1 & $\mathbf{0 . 6 6}$ & 0.13 & 0.02 & 0.17 & 0.02 & 饶河 & 状态 1 & 0.48 & 0.19 & 0.06 & 0.26 & 0.02 \\
& 状态 2 & 0.32 & $\mathbf{0 . 6 5}$ & 0.02 & 0.01 & 0 & & 状态 2 & 0.16 & $\mathbf{0 . 6 8}$ & 0.09 & 0.02 & 0.04 \\
& 状态 3 & 0.27 & 0 & 0.18 & $\mathbf{0 . 5 5}$ & 0 & & 状态 3 & 0.11 & 0.28 & 0.43 & 0.15 & 0.02 \\
& 状态 4 & 0.42 & 0.03 & 0.01 & $\mathbf{0 . 5 5}$ & 0 & & 状态 4 & 0.10 & 0.05 & 0.02 & $\mathbf{0 . 7 2}$ & 0.11 \\
& 状态 5 & 0.43 & 0.43 & 0 & 0 & 0.14 & & 状态 5 & 0.30 & 0.21 & 0 & 0.19 & 0.30 \\
抚河 & 状态 1 & 0.47 & 0.24 & 0.05 & 0.21 & 0.03 & 修河 & 状态 1 & 0.37 & 0.24 & 0.06 & 0.24 & 0.08 \\
& 状态 2 & 0.18 & $\mathbf{0 . 6 7}$ & 0.12 & 0.01 & 0.02 & & 状态 2 & 0.14 & $\mathbf{0 . 6 6}$ & 0.13 & 0.04 & 0.03 \\
& 状态 3 & 0.23 & 0.15 & 0.38 & 0.23 & 0 & & 状态 3 & 0.25 & 0.13 & 0.33 & 0.25 & 0.04 \\
& 状态 4 & 0.12 & 0.03 & 0.02 & $\mathbf{0 . 6 6}$ & 0.17 & & 状态 4 & 0.16 & 0.04 & 0.04 & $\mathbf{0 . 6 5}$ & 0.12 \\
& 状态 5 & 0.18 & 0.20 & 0.02 & 0.21 & 0.39 & & 状态 5 & 0.11 & 0.20 & 0 & 0.31 & 0.38 \\
信江 & 状态 1 & 0.43 & 0.22 & 0.04 & 0.27 & 0.04 & & & & & & & \\
& 状态 2 & 0.21 & $\mathbf{0 . 6 9}$ & 0.06 & 0.04 & 0.01 & & & & & & & \\
& 状态 3 & 0.18 & 0.24 & 0.39 & 0.18 & 0 & & & & & & & \\
& 状态 4 & 0.15 & 0.06 & 0.02 & $\mathbf{0 . 6 9}$ & 0.08 & & & & & & & \\
& 状态 5 & 0.19 & 0.25 & 0 & 0.25 & 0.31 & & & & & & & \\
\hline
\end{tabular}

数字黑体表示一步转移概率大于 0.5 .

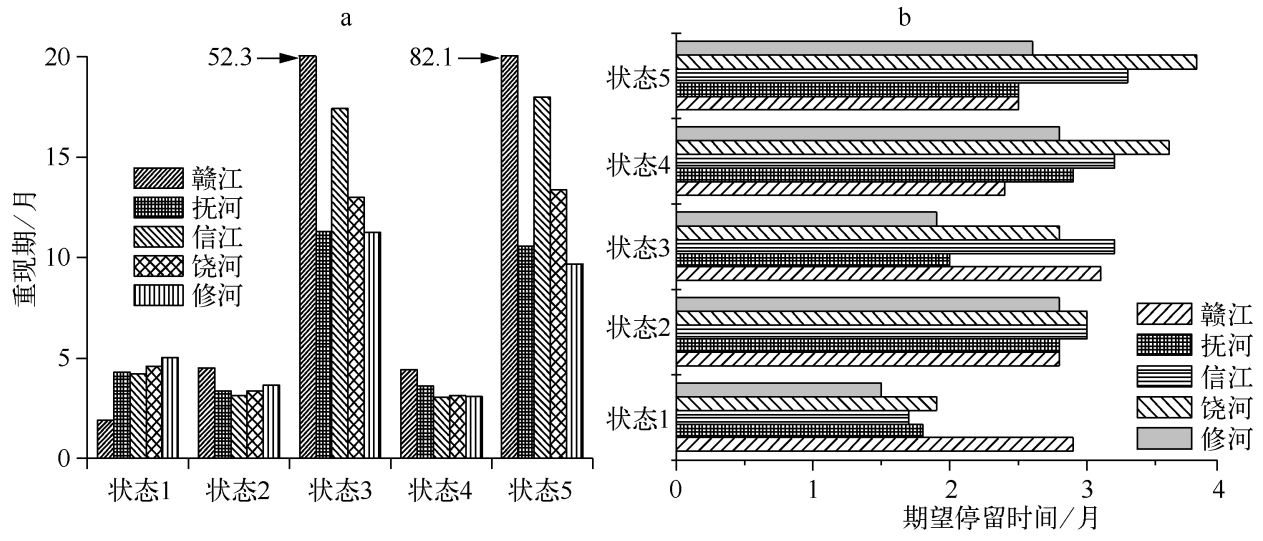

图 5 鄱阳湖流域各站点 SRI-SPI 分级的重现期 ( a ) 和期望停留时间 (b)

Fig. 5 The return period(a) and expected residence time(b) of a given SRI-SPI class developed for individual locations in Lake Poyang Basin

图 6B 是鄱阳湖流域干旱灾害演变雷达图, 修河流域是鄱阳湖流域各河流状态 1 、状态 2 到状态 3 、状态 4 的平均首达时间是最小的, 这表明修河流域在干旱灾害形成中危害最大, 抚河流域在干旱演变的过程中 (状态 4 到状态 5 ) 的平均首达时间最小 (11.7 个月), 其干旱危害最大. 赣江流域在干旱灾害形成和干旱灾 

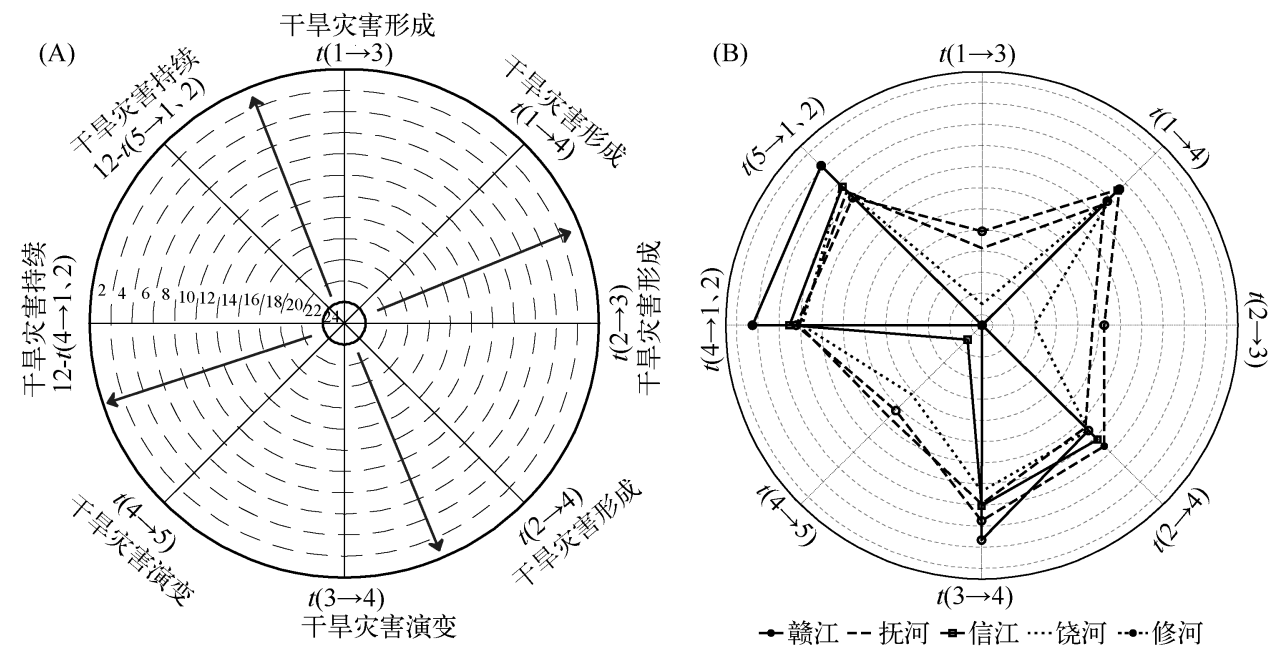

图 6 鄱阳湖流域各站点平均首达时间演绎干旱灾害形成、演化和持续性

Fig. 6 The interpretation of the developed first passage of times in terms of hazard of drought formation, evolution and persistence and drought hazard developed in Lake Poyang Basin

害演变 (状态 4 到状态 5 ) 的过程中干旱危害最小, 但是在干旱灾害持续(状态 5 到状态 1 ) 的平均首达时间 最小 (2.7 个月), 干旱危险最大. 饶河流域与赣江类似, 在干旱灾害形成中危害小, 但是在干旱灾害持续中 ( 状态 4 到状态 1 ) 干旱危险最大.

\section{5 干旱灾害预测}

图 7 是预测了初始状态是非水文干旱状态 (状态 1 、状态 2 、状态 3 ) 到水文干旱状态 ( 状态 4 、状态 5 ) 的 未来 6 个月的发生概率. 随着预测时间的增加, 非水文干旱转移到水文干旱的概率增加, 但是赣江流域部分 状态转移随着时间的增加而降低. 从非水文干旱转移到状态 4 的概率 $(0.25)$ 远大于非水文干旱转移到状态 5 的概率 $(0.06)$, 这表明鄱阳湖流域在非水文干旱状态下易发生水文气象干旱. 修河流域大部分从非水文 干旱转移到水文干旱的概率远高于其他流域, 其中状态 1 转移到状态 4 的概率低于信江流域和饶河流域 (图 7B F). 信江流域在非水文干旱状态转移到状态 5 的概率是全流域最低的, 然而信江流域非水文干旱 状态转移到水文气象干旱状态的概率较高, 表明信江流域非水文干旱状态很难发生状态 5 , 但是易发生水文 气象干旱. 赣江流域从非水文干旱转移到水文干旱的概率是最低的 (图 7A C、7F), 这表明赣江流域在正 常或者湿润状态下很难发生水文干旱, 赣江流域在状态 3 的情况下前 3 个月极易发生水文气象干旱, 但是随 后发生水文气象干旱概率降到全流域最低(图 7E).

\section{4 结论}

运用基于降水和水资源短缺的 $S P I$ 和 $S R I$ 干旱指数, 建立了包含气象干旱指标和水文干旱指标的二维 变量的干旱状态, 通过一阶马尔科夫链模型对二维变量干旱指数的等级进行概率、重现期和历时分析, 同时 预测未来 6 个月非水文干旱到水文干旱的概率, 得到以下结论:

1 ) 建立的水文气象干旱指数, 从干旱灾害形成、演变和持续 3 方面对干旱灾害进行研究, 修河流域在干 旱形成中危害大, 抚河流域在干旱演变中危害大, 赣江流域和饶河流域在干旱持续中危害大, 赣江流域在干 旱灾害形成和干旱灾害演变的过程中干旱危害最小. 鄱阳湖流域以水文气象干旱为主, 单独的气象干旱或 者水文干旱发生频率低. 赣江流域在鄱阳湖 “五河” 流域中面积最大, 流域森林覆盖率高和水库及其库容量 也最大 ${ }^{[7]}$, 赣江流域抵御干旱的能力就远大于其他流域, 因此赣江流域干旱灾害在发展和演变过程中的危 害远低于其他流域, 流域面积大的赣江在干旱持续过程中回到正常或者湿润状态历时大于其他流域, 其干 旱灾害过程中危害最大.

2) 赣江流域在状态 1 和状态 3 历时最长, 抚河流域和修河流域在状态 2 和状态 4 历时最长, 信江流域 

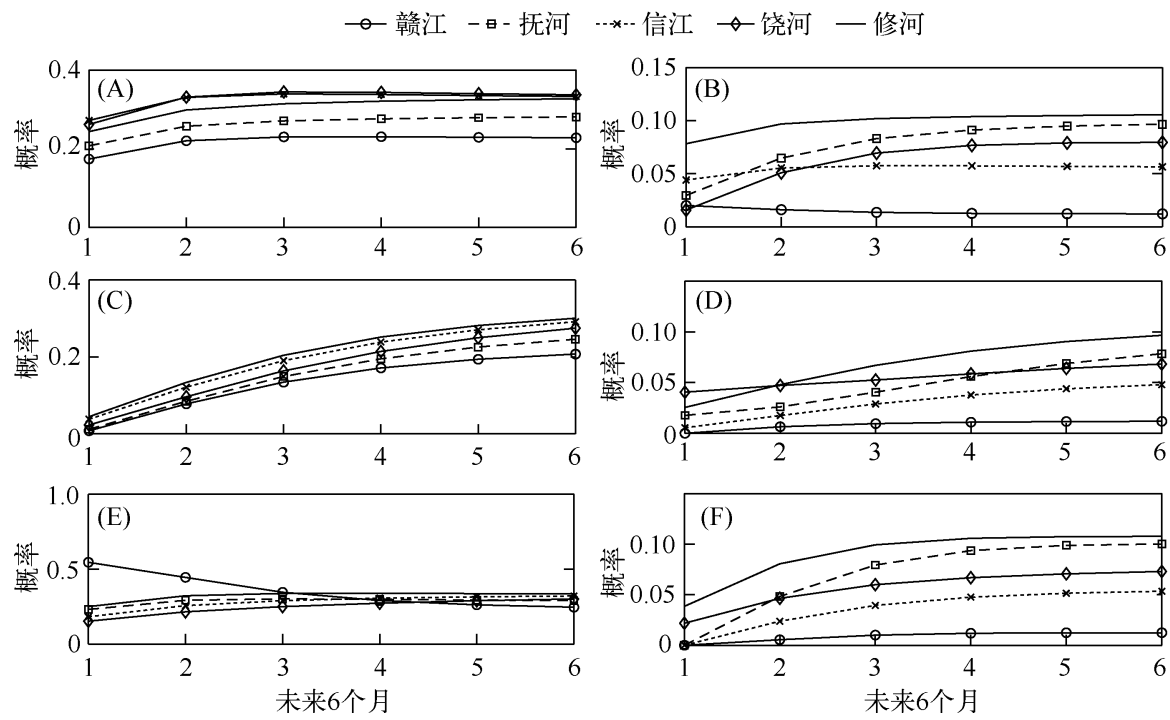

图 7 预测状态 1 一状态 3 综合干旱指数在未来 6 个月的水文干旱 (状态 4 -状态 5 ) 发生 概率 $(A$ : 表示状态 1 一状态 4 ; B : 表示状态 1 一状态 5 ; C : 状态 2 - 状态 4; D : 状态 2 一状态 5 ;E: 状态 3 -状态 4 ; F : 状态 3 -状态 5 )

Fig. 7 Probability to arrive at hydrological dry conditions (class 4 and 5 ) in 1, 2 and 3moths time horizon starting from: (A-B) : normal hydrological conditions ( class 1), ( C-D) wet conditions ( class 2) and (E-F) wet hydrological and dry meteorological conditions ( class 3 )

和饶河流域在状态 4 和状态 5 历时最长. 鄱阳湖流域连续湿润或者干旱的概率最大, 湿润状态 (状态 2 ) 与 水文干旱 (状态 4 、状态 5 ) 的相互转移概率低, 赣江流域状态 2 、状态 3 和状态 5 发生的概率低于其他流域. 赣江流域面积大, 干旱发生频率低 ${ }^{[11]}$, 鄱阳湖流域西北部的信江和饶河干旱发生频率最高且强度较大 ${ }^{[11]}$, 流域面积和干旱频率、强度的时空分布不均引起了状态转移频率分布的差异性.

3 ) 在长期干旱预测中, 鄱阳湖流域从状态 2 到状态 4 或者状态 5 的概率最低, 状态 1 或者状态 3 到达 状态 4 的概率最大. 修河流域从非水文干旱易发生水文干旱, 赣江流域在正常或者湿润状态下很难发生水 文气象干旱, 但是赣江流域在状态 3 的情况下前 3 个月极易发生水文气象干旱, 随后发生水文气象干旱的概 率降到全流域最低.

\section{5 参考文献}

[ 1 ] Zhang Q, Sun P, Chen XH et al. Hydrological extremes in the Lake Poyang Basin, China: changing properties, causes and impacts. Hydrological Processes, 2011, 25: 3121-3130.

[ 2 ] 张 强, 孙 鹏, 江 涛. 鄱阳湖流域水文极值演变特征、成因与影响. 湖泊科学, 2011,23(3): 445-453. DOI 10. $18307 / 2011.0319$.

[ 3 ] 叶许春, 张 奇, 刘 健等. 鄱阳湖流域天然径流变化特征与水早灾害. 自然灾害学报, 2012,21(1): 140-147.

[ 4 ] 闵 骞. 20 世纪 90 年代鄱阳湖洪水特征的分析. 湖泊科学, 2002,14(4) : 323-330. DOI 10.18307/2002.0405.

[ 5 ] 孙 鹏, 张 强, 陈晓宏. 基于 Copula 函数的鄱阳湖流域极值流量遭遇频率及灾害风险. 湖泊科学, 2011,23 (2) : 183-190. DOI 10.18307/2011.0204.

[ 6 ] 刘 健, 张 奇, 左海军等. 鄱阳湖流域径流模型. 湖泊科学, 2009,21(4) : 570-578. DOI 10.18307/2009.0417.

[ 7 ] 孙 鹏, 张 强, 陈晓宏等. 鄱阳湖流域水沙时空演变特征及其机理. 地理学报, 2010,65(7): 828-840.

[ 8 ] 闵 骞, 占腊生. $1952-2011$ 年鄱阳湖枯水变化分析. 湖泊科学, 2012,24 (5): 675-678. DOI 10. 18307/ 2012. 0505 . 
[9] 孙 鹏, 张 强, 陈晓宏. 鄱阳湖流域枯水径流演变特征、成因与影响. 地理研究, 2011,30(9): 1702-1712.

[10]闵㖄, 刘健. 鄱阳湖区域极端降水异常的特征及成因. 湖泊科学, 2011,23 (3)：435-444. DOI 10. 18307/ 2011.0318.

[11] 闵 屾, 严蜜, 刘 健. 鄱阳湖流域干旱气候特征研究. 湖泊科学, 2013,25(1): 65-72. DOI 10. 18307/ 2013.0109.

[12] 胡振鹏, 林玉茹. 气候变化对鄱阳湖流域干旱灾害影响及其对策. 长江流域资源与环境, 2012,21(7): 897-904.

[13] Mishra AK, Singh VP. A review of drought concepts. Journal of Hydrology, 2010,391 (1) : 202-216.

[14] Shukla S, Wood AW. Use of a standardized runoff index for characterizing hydrologic drought. Geophysical Research Letters, $2008, \mathbf{3 5}(2)$ : $41-46$.

[15] McKee TB, Doesken NJ, Kleist J. The relationship of drought frequency and duration to time scales. Eighth Conference on Applied Climatology, Anaheim, CA. Am. Meteor. Soc., Boston, 1993: 179-184.

[16] 李剑锋, 张 强, 陈晓宏等. 基于标准降水指标的新疆干旱特征演变. 应用气象学报, 2012,23(3): 322-330.

[17] Eyton JR. Complementary-color, two-variable maps. Annals of the Association of American Geographers, 1984,74(3): 447-190.

[18] 王文圣, 丁 晶, 金菊良. 随机水文学. 北京: 中国水利水电出版社, 2008: 20-23.

[19] 施仁杰. 马尔科夫链基础及其应用. 西安: 西安电子科技大学出版社, 1992: 40-45.

[20] Wilks DS. Statistical methods in the atmospheric sciences. Access Online via Elsevier, 2011.

[21] 王怀清, 赵冠男, 彭 静等. 近 50 年鄱阳湖五大流域降水变化特征研究. 长江流域资源与环境, 2009,18(7): 615-619. 